Arch. Histol. Cytol., Vol. 52, Suppl. (1989) p. $63-68$

\title{
Expression of the Cholecystokinin Gene in the Neuron and Paraneuron*
}

\author{
Yasuo Takahashi, Ryozo Kuwano, Hiroshi Usui, Kazuaki Araki ${ }^{1}$, Makoto Hasegawa ${ }^{2}$ and \\ Yoshiaki SUZUKI ${ }^{3}$ \\ Department of Neuropharmacology ${ }^{1}$, Brain Research Institute, Niigata University; Department of Psychiatry ${ }^{2}$, Niigata Univer- \\ sity School of Medicine, Niigata; and Department of Developmental Biology ${ }^{3}$, National Institute for Basic Biology, Okazaki, \\ Japan
}

Summary. Cholecystokinin (CCK), the long known gut hormone has recently been found in the brain and suggested to be a neurotransmitter or neuromodulator. In order to clarify the structure of the CCK precursor, we cloned the cDNA to mRNA of rat brain. We determined the nucleotide sequence of the inserted $\mathrm{CDNA}$ and deduced the amino acid sequence and proteolytic cleavage sites of the CCK precursor. The availability of CCK cDNA probes allowed us to examine the levels of CCK mRNA in the brain and intestine. CCK mRNA was barely detectable in the fetal brain, but started to increase postnatally and attained a plateau after 20-30 days. The level of CCK mRNA was the highest in the frontal cortex, followed by those of the hippocampus and striatum. The cerebellum contained only negligible CCK mRNA. Furthermore, we succeeded in cloning the CCK gene and revealed its structure which contained three exons interrupted by two introns. The size of this gene spanned about $7 \mathrm{kbp}$. The transcription initiation sites were determined by using $\mathrm{S} 1$ nuclease mapping and a primer extension procedure, showing evidence for the existence of the major and minor start sites. To analyze the mechanism for CCK gene expression in the neuron and paraneuron, we tried to examine the transcription of the DNA fragments from CCK gene by an in vitro cell free system. These experiments confirmed the existence of two transcription start sites. From experiments with the deleted mutants of DNA fragments, we could deduce the promoter sequence. Assuming the presence of the cell-specific regulation factor in the nuclear extract from the rat brain, we examined a brain-specific DNA binding protein in the rat brain nuclear extract by a gel shift assay and DNase footprinting assay with several DNA fragments from 5'-flanking region of the CCK gene. A brain nuclear protein could bind to a promoter region. The exact binding site was determined with several synthetic oligodeoxynucleotides and their mutants. Currently we are attempting to purify this brain nuclear factor and to examine the regulatory function of this factor in cell-free transcription experiments.

\section{cDNA CLONING AND PROCESSING OF CCK PRECURSOR}

Cholecystokinin (CCK) has long been recognized as a gut hormone. Recently several researchers reported that CCK is also found in the brain of mammals, particularly in neurons, leading to suggestions that CCK may act as a neurotransmitter or a neuromodulator (BEINFELD et al., 1983; DE BELLEROCHE and DOCKRAY, 1984, VANDERHAEGEN and CRAWLEY, 1985). About six years ago, we attempted to clone the cDNA to mRNA of rat brain CCK in order to clarify the structure of the CCK precursor and its processing. At that time, the structure of the CCK precursor had not yet been clarified (REHFELD, 1981); only the amino acid sequence of CCK 58 had been determined (EYSSELEIN et al., 1982). We synthesized oligodeoxynucleotide corresponding to five amino acids of CCK8 and used this nucleotide as a probe to screen a brain cDNA library by colony-hybridization. From a cDNA clone, we determined the nucleotide sequence of CCK cDNA and deduced the amino acid sequence of this CCK precursor (KUWANO et al., 1984).

Findings were that the coding region contained 345 nucleotides, encoding 115 amino acids. The molecular weight of this precursor was calculated to be 12800 daltons. The 3'-noncoding region was $263 \mathrm{bp}$ long and contained the poly(A) signal. The 5'-noncoding region contained $110 \mathrm{bp}$. The size of our cDNA was $718 \mathrm{bp}$ long. This was much larger than that of other $\mathrm{cDNA}$ from rat medullary thyroid carcinoma cells or pig brains, which was found at almost the same time (DESChEnEs et al., 1984; Gubler et al., 1984). The CCK precursor contains a 28 amino acid signal peptide and 12 additional amino acids at the carboxyl terminus. Proteolytic processing from the CCK pre-

\footnotetext{
*This study was carried out under the NIBB Cooperative Research Program (87-121, 88-119).
} 


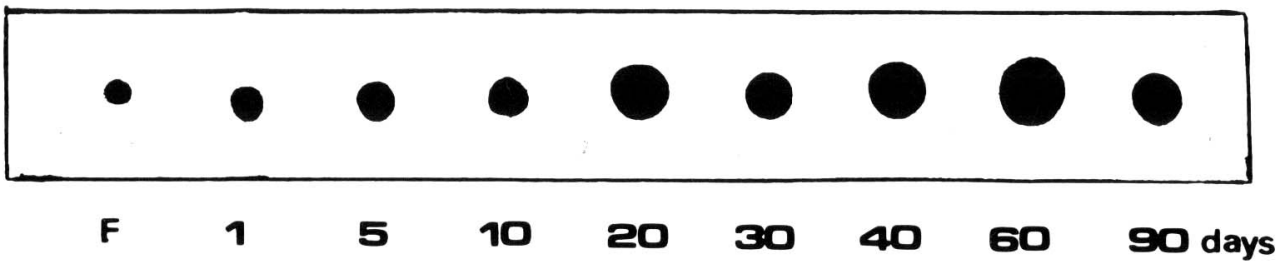

Fig. 1. Developmental changes of CCK mRNA in rat brains. Cytoplasmic RNA from developing rat brains, fetal $(F)$ and postnatal (1-90 days), spotted onto nitrocellulose membrane and hybridized with ${ }^{32} \mathrm{P}-\mathrm{CCK} \mathrm{cDNA}$. The concentration of RNA was $10 \mu \mathrm{g}$.

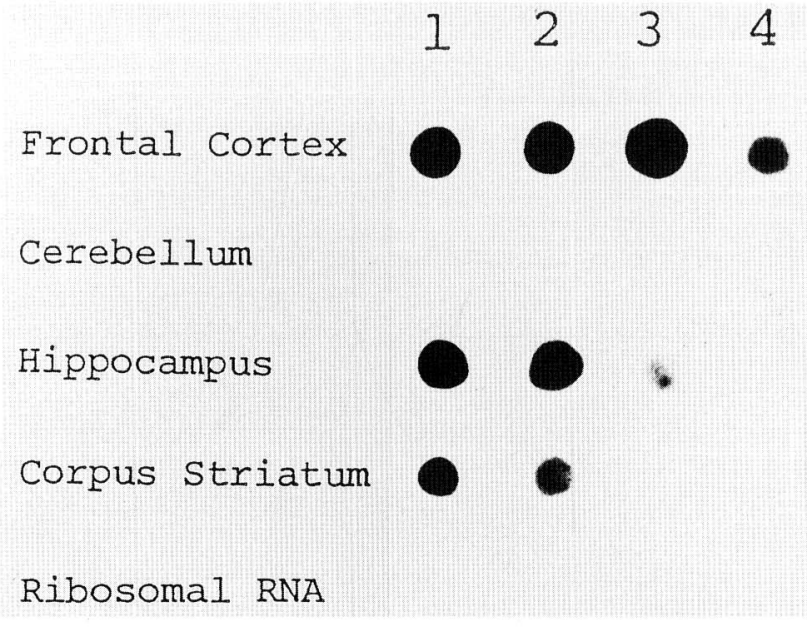

Fig. 2. Regional distribution of CCK mRNA in rat brains. The cytoplasmic RNA from various regions of rat brains was analyzed by dot-blot hybridization using ${ }^{32} \mathrm{P}-\mathrm{CCK}$ cDNA. The concentrations of cytoplasmic RNA were 12.5 (1), 6.25 (2), 3.13 (3) and $1.56 \mu \mathrm{g}$ (4).

cursor produces CCK 58, CCK 39, CCK 33 and CCK 8. The cleavages occur immediately carboxyl-terminal to a single basic amino acid (Arg). The conversion of the CCK precursor to CCK also requires cleavage and modification at the carboxyl-terminus.

\section{DEVELOPMENTAL AND REGIONAL CHANGES OF CCK mRNA IN THE RAT BRAINS}

The availability of a CCK cDNA probe allowed us to examine the level of CCK mRNA in the tissues (HASEGAWA et al., 1986). A Northern blot analysis of rat brain poly $(\mathrm{A})^{+} \mathrm{RNA}$ with $\mathrm{CCK}$ cDNA showed that the size of CCK mRNA was approximately 850 bases long. Furthermore, we examined the developmental changes of CCK mRNA in the rat brains. CCK mRNA was barely detectable in the fetal brain, but started to increase postnatally and reached a plateau after 20-30 days (Fig. 1). Using a CCK cDNA probe we also analyzed the regional distribution of CCK mRNA in an adult rat brain. The mRNA level of the frontal cortex was the highest and that of the cerebellum was negligible. The levels in the hippocampus and striata were considerably lower than that of the frontal cortex (Fig. 2). This result was in agreement with our data on the regional distribution of CCK in rat brains. These data suggested the transcriptional regulation of CCK gene expression. Recently GuBLER et al. (1987) reported evidence for the existence of CCK mRNA in pig cerebellum.

\section{STRUCTURE OF CCK GENE}

As the first step to characterize the CCK gene sequence, we analyzed rat genomic DNA by a Southern blot analysis using labeled CCK CDNA as a probe. The cDNA probe hybridized to a single band or two bands per DNA digest, showing the existence of a sequence corresponding to $\mathrm{CCK}$ cDNA in total genomic DNA and a single copy per haproid genome. We there succeeded in cloning the rat CCK gene from the rat Charon 4A genomic library using plaque hybridization with CCK cDNA (KUwANO et al., $1989 \mathrm{a}, \mathrm{b})$. Figure 3 shows the structure and a restriction endonuclease map of the CCK gene. It was found that rat CCK gene contains three exons interrupted by two introns. The size of this gene spanned about 7 $\mathrm{kbp}$. The exon I contained 5'-noncoding region, while the exon II contained the last two bases of 5'noncoding region and the coding region corresponding to amino terminal 72 amino acids. The exon III consisted of the nucleotide sequence corresponding to the carboxyl terminal peptide and the 3'-noncoding region. The intron 1 was $1 \mathrm{kbp}$ long and the size of the intron 2 was $2 \mathrm{kbp}$ (DESCHENES et al., 1985; TAKAHASHI et al., 1985; KUWANO et al., 1989a, b). In order to determine the exact transcription start site 


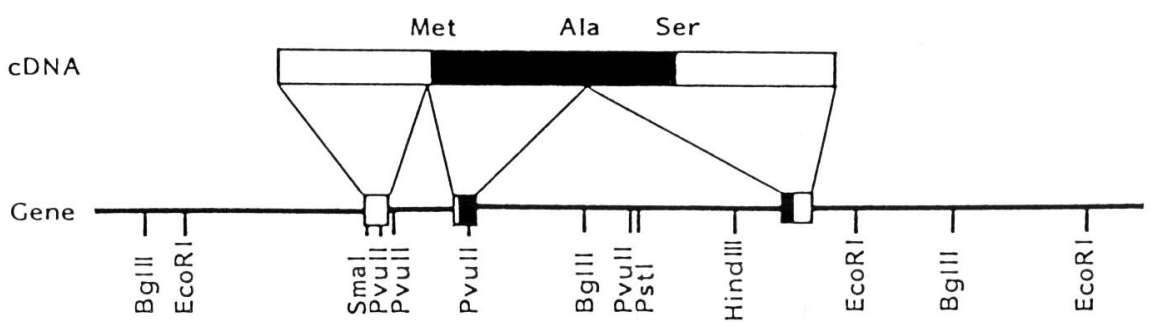

Fig. 3. Structure of the CCK gene and cDNA. cDNA and corresponding exons are depicted as boxes: the closed boxes indicate the coding region and the open boxes the non-coding regions.

Fig. $4 \mathbf{a}$ and $\mathbf{b}$. Northern blot analysis. Rat brain poly $(\mathrm{A})^{+}$RNA (lane 1, $5 \mu \mathrm{g}$; lane $2,10 \mu \mathrm{g}$ ) was hybridized with probe I or probe II. The AluI-AluI fragment was used as probe I and the PstI-PvuII was used as probe II. After washing out probe I, the same filter was re-hybridized with probe II. The labeled $\phi \times 174$ DNA digested with TaqI was used as size markers (lane $M$ ). The boxes indicate exons; the open boxes show the non-translated regions and the closed boxes indicate the translated regions.
Probe I

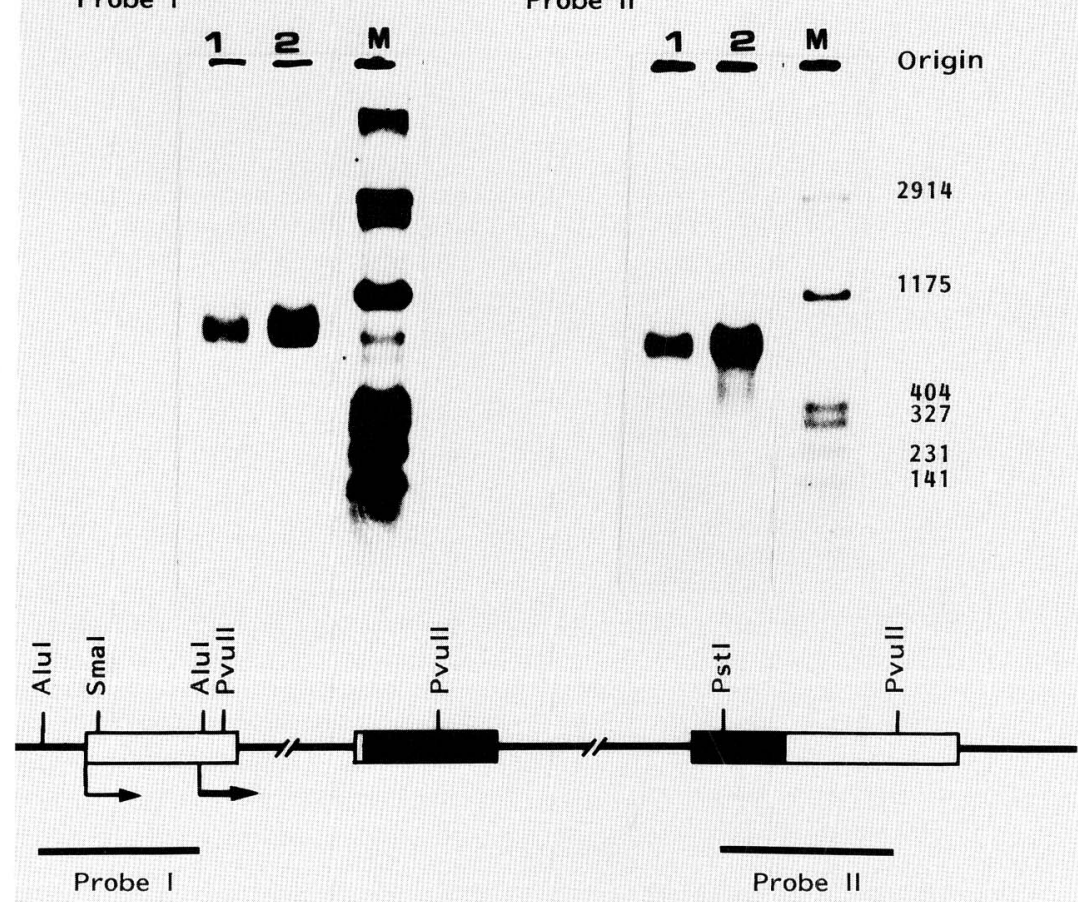

Probe II a of CCK gene, we used a primer extension procedure and S1 nuclease mapping. cDNA synthesis was carried out with a HpaII-Dde I (-103- - 58) fragment as a primer using avian myeloblastosis reverse transcriptase. The longest primed product was about 120 bases, excluding the HpaII-Dde I 47 bases fragment as a primer. For S1 nuclease mapping, rat poly $(\mathrm{A})^{+}$ RNA and single stranded AvaII-PvuII fragment (420 bp) were annealed and the RNA-DNA hybrid then digested with $\mathrm{S} 1$ nuclease. Two protected bands were observed in the presence of cerebral poly $(\mathrm{A})^{+} \mathrm{RNA}$. There was, however, no protected band with cerebellar poly $(\mathrm{A})^{+} \mathrm{RNA}$ and tRNA. The intense band corresponded to A in the sequence 5'-TTCACTG-3' and the faint band corresponded to $A$ in the sequence 5'GTCATT-3'. The existence of two CCK mRNA was confirmed by Northern blot analysis with two region-specific probes (probe 1-AluI-AluI fragment and probe 2-PstI-PvuII fragment). We were able to find two bands. The size of one band was $100 \mathrm{~b}$ larger than that of the other (Fig. 4). However, the concentration of the large mRNA accounts for about $3 \%$ of that of the total CCK mRNA in the rat brain by semiquantitative dot blot hybridization. At present we have not been able to clarify the physiological roles of two CCK mRNA in the expression of CCK gene in the brain (KUWANO et al., 1989a).

\section{In vitro transcription of $\mathrm{CCK}$ gene}

In order to analyze the mechanism for CCK gene 


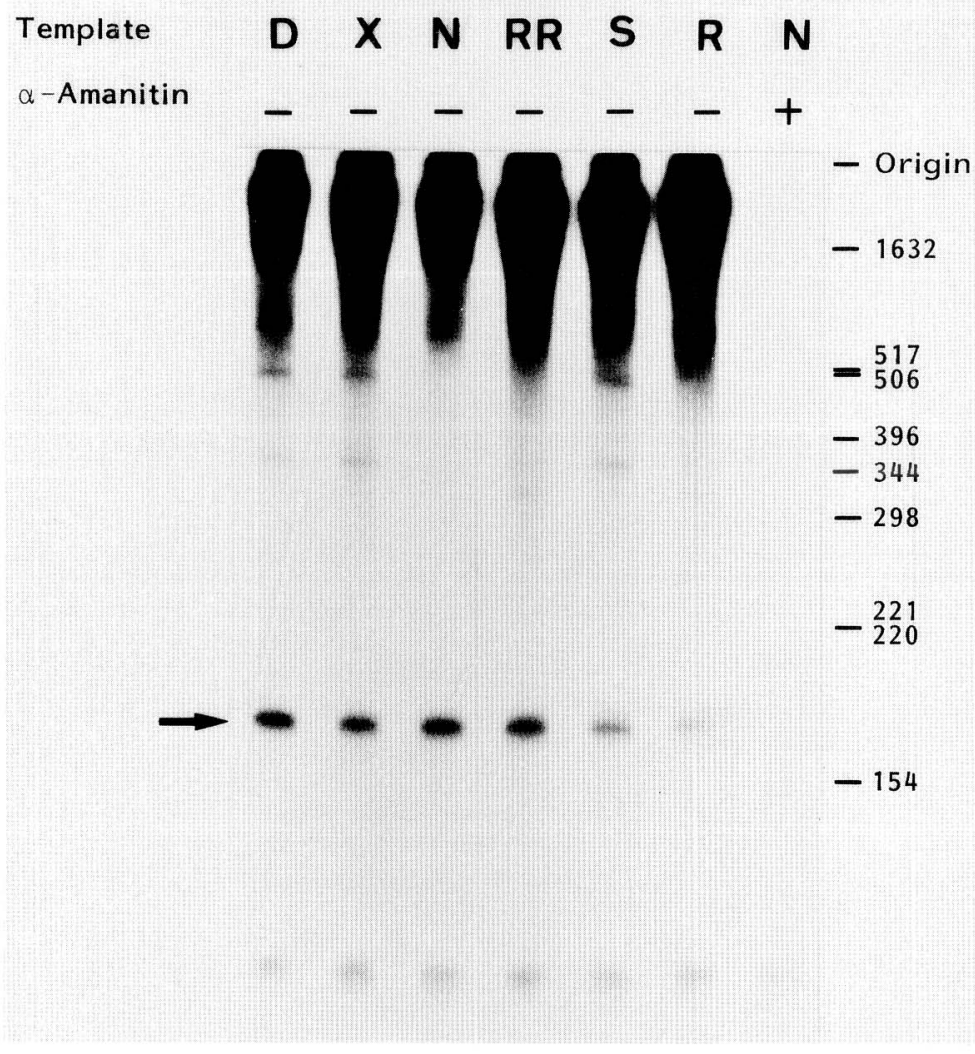

Fig. 5. Transcription of the CCK deletion mutant genes. The deletion mutant genes, pSP-DP $(D)$, pSP-NPP $(N)$, pSP-RRPP $(R R)$, pSP-SPP $(S)$ and pSP-RPP $(R)$ were digested with BamHI and used as truncated templates for transcription. Transcription was done in the HeLa cell extract. The expected primary transcript at position -59 is 170 nucleotides long (arrow).

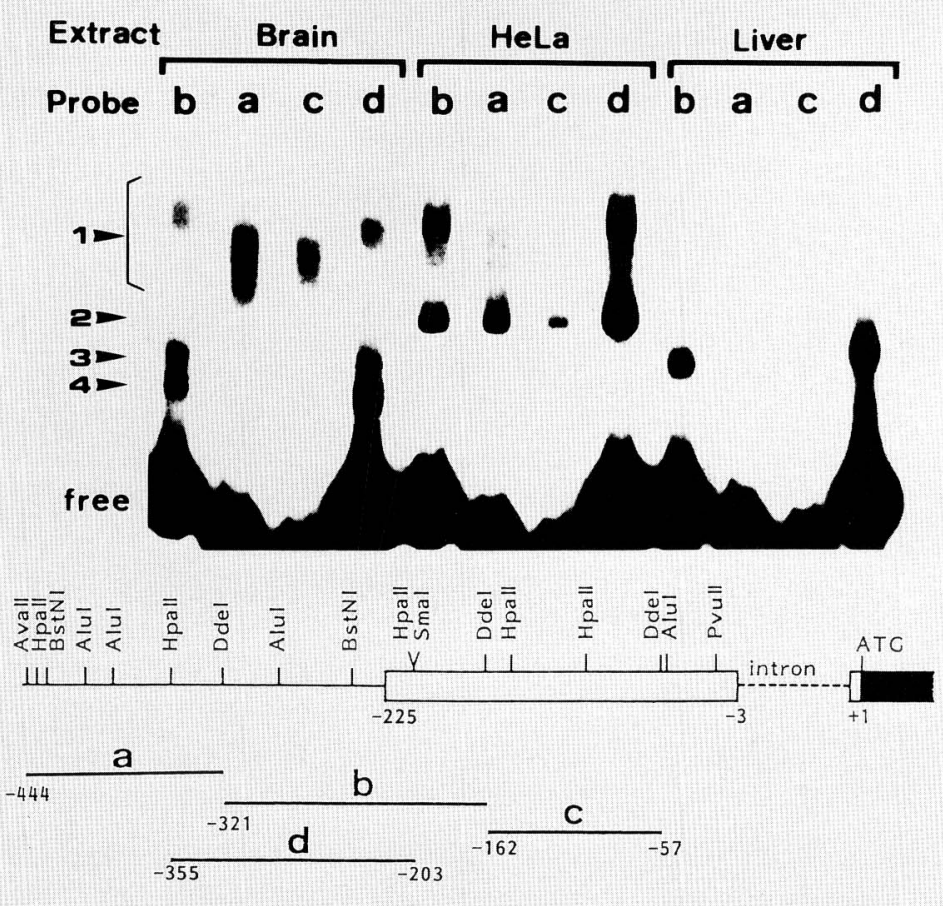

Fig. 6. Gel-shift assay. Protein-DNA complexes were formed with rat brain and liver nuclear extracts and HeLa cell extracts. The extracts were incubated with the restriction fragments $a, b, c$ and $d$ which are shown at the bottom. 
Fig. 7. Gel-shift assay with the mutated oligodeoxynucleotides. The brain extract was incubated with the mutated oligodeoxynucleotides $\mathrm{Zm}-1$ and $\mathrm{Zm}-2$, in the absence $(-)$ or presence of competitors, $Z, Z \mathrm{~m}-1, \mathrm{Zm}-2$, Y and $X$. The numbers on the left indicate the positions of migration retarded bands.
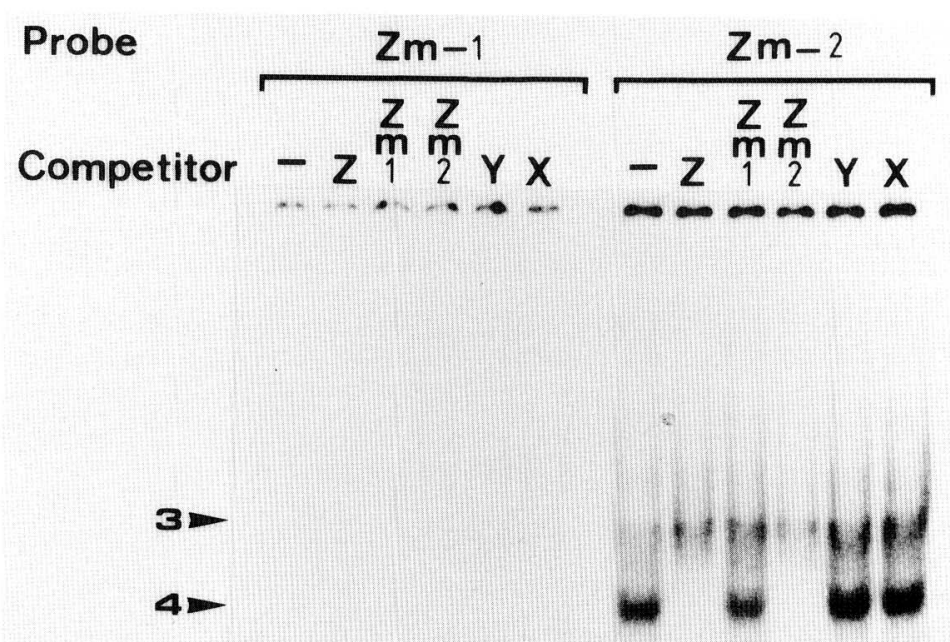

expression, we examined the transcription of the DNA fragments from the CCK gene by an in vitro cell free system. We used HeLa cell extracts prepared by Manley's procedure (MANLEY et al., 1980) and rat brain nuclear extracts prepared by Schibler's procedure (GoRSKI et al., 1986) for the cell free transcription experiments. We obtained faithful transcripts: about $200 \mathrm{~b}$ transcript from PvuII truncated DNA fragment and $350 \mathrm{~b}$ faint and $160 \mathrm{~b}$ dense transcripts from BamHI truncated DNA fragment. These mRNA bands disappeared by the addition of $\alpha$-amanitin. These results also confirmed the existence of two transcription start sites for the CCK gene. Since the larger mRNA was very little in amount as described above, it was difficult to analyze the promoter activity for the transcription of CCK gene with a minor initiation site, -225 . Therefore, we attempted to determine the promoter region for the major transcription start site, -59 , and prepared the deleted mutants of 5'-flanking region of CCK gene for the transcription experiments. When we examined the effects of the deletion of the 5'-flanking region on the transcription of the CCK gene in the HeLa cell or the brain cell free system, the 5'-flanking region between -254 and -105 was necessary for full promoter activity. This region contains TATAbox-like and GC-box-like sequences (Fig. 5). The curve of the deletion effects on the transcription of CCK gene was almost similar between $\mathrm{HeLa}$ and rat brain cell free systems.

\section{Trans-acting regulatory factors}

Assuming the presence of the cell-specific transacting regulatory factor for the $\mathrm{CCK}$ gene in the nuclear extract of the rat brain, we examined a brain-specific DNA binding protein in the rat brain nuclear extract by the gel-shift assay (KUWANO et al., 1989b). For this purpose we prepared the DNA fragments ( $a, b, c$ and d) from the 5'-flanking region of CCK gene and ${ }^{32} \mathrm{P}$-labeled them. After incubation of these DNA fragments and the nuclear extracts of the brain, liver or HeLa cell, gel-shift assay of the reaction product was carried out. We found four DNAprotein complexes binding to ${ }^{32} \mathrm{P}$-labeled $\mathrm{b}$ or $\mathrm{d}$ fragment (Fig. 6). The band 4 may be brain-specific. The competition effect of unlabeled DNA fragments on the binding pattern of the brain nuclear extract also showed that the brain nuclear extract contained a factor protein binding to the DNA fragment $(-321$ -203). To examine in detail the brain nuclear proteins binding to the DNA fragment $(-321--203)$, we carried out DNase footprinting analysis of this 
binding. We found that the brain nuclear protein bound three regions of this DNA fragment. Furthermore, in order to determine the precise binding site, we synthesized three double stranded oligodeoxynucleotides of each $20 \mathrm{bp}(\mathrm{X}, \mathrm{Y}$ and $\mathrm{Z}$ ) from the protected regions in the DNase footprinting analysis. By gel-shift assay with brain nuclear extract and these oligodeoxynucleotides, only $Z(-244--226)$ formed a unique complex. $\mathrm{X}$ or $\mathrm{Y}$ did not compete with this complex formation of $Z$. We then synthesized two mutants of $Z$ fragment $(\mathrm{Zm} 1$ and $Z \mathrm{~m} 2)$. In these mutants, $\mathrm{C}$ was changed to $\mathrm{A}$ according to the results with methylation interference. $\mathrm{Zml}$ lost the protein binding activity, while $\mathrm{Zm} 2$ bound to the brain nuclear protein. Therefore, CC $(-230$ and -231$)$ in the $Z$ fragment might be the most important (Fig. 7). It seemed of physiologically importance that a protein factor (band 4) increased postnatally in a brain nuclear extract by gel shift assay with $d$ fragment.

\section{CONCLUSION}

From the above results, we believe that this DNA binding protein is a candidate for the trans-acting regulatory factor in the specific expression of the CCK gene in the rat brain. Recently, we have attempted to purify this brain nuclear factor by using heparin agarose chromatography and DNA affinity chromatography. Since recently we were able to isolate a pure protein showing a single band on SDSPAGE, we plan to examine the regulatory function of this factor in cell-free transcription experiments of the CCK gene. Furthermore, we intend to carry out the cloning of cDNA for this factor protein and cotransfection of CCK gene and cDNA for this factor into the cultured cells. As a further step, we shall examine the enhancer sequence in the 5'-flanking region or the introns and other brain nuclear protein binding to the enhancer.

\section{REFERENCES}

Beinfeld, M. C.: Cholecystokinin in the central nervous system: A minireview. Neuropeptides 3: 411-427 (1983).

De Belleroche, J. and G. J. DockraY: Cholecystokinin (CCK) in the nervous system. Verlag Chemie, Weinheim, 1984.

Deschenes, R. J., L. J. LoRENZ, R. S. HaUn, B. A. Roos, K. J. Collier and J. E. Dixon: Cloning and sequence analysis of a cDNA encoding rat preprocholecystokinin. Proc. Nat. Acad. Sci. USA. 381: 726-730 (1984).
Deschenes, R. J., R. S. Haun, C. L. Funckes and J. E. DIxon: A gene encoding rat cholecystokinin. J. Biol. Chem. 260: 1280-1286 (1985).

Eysselein, V. E., J. R. Reeve, J. E. Shively, D. Hauke and J. H. W ALSH: Partial structure of a large canine cholecystokinin (CCK-58): Amino acid sequence. Peptides 3: 687-691 (1982).

Gorski, K., M. Carneiro and U. Schibler: Tissuespecific in vitro transcription from the mouse albumin promoter. Cell 47: 767-776 (1986).

Gubler, U., A. O. Chua, B. J. Hoffman, K. J. Collier and J. ENG: Cloned cDNA to cholecystokinin mRNA predicts an identical preprocholecystokinin in pig brain and gut. Proc. Nat. Acad. Sci. USA. 81: 4307-4310 (1984).

Gubler, U., A. O. Chua, D. Young, Z.-W. Fan and J. ENG: Cholecystokinin mRNA in porcine cerebellum. J. Biol. Chem. 262: 15242-15245 (1987).

Hasegawa, M., H. Usui, K. Araki, R. Kuwano and Y. TAKAhASHI: Developmental and region changes of cholecystokinin mRNA in rat brains. FEBS Lett. 194: 224-226 (1986).

Kuwano, R., K. Araki, H. Usui, T. Fukui, E. Ohtsuka, M. IKEHARA and Y. TAKAHASHI: Molecular cloning and nucleotide sequence of cDNA coding for rat cholecystokinin precursor. J. Biochem. 96: 923-926 (1984).

Kuwano, R., K. Araki, H. Usui, Y. Suzuki and Y. TAKAhAShI: Transcription of rat cholecystokinin gene initiates at the multiple sites. submitted (1989a).

Kuwano, R., K. Araki, Y. Takahashi and Y. Suzuki: Brain nuclear factor that binds specifically to the 5'. flanking region of cholecystokinin gene. submitted (1989b).

Manley, J. L., A. Fire, A. Cano, P. A. Sharp and M. L. GEFTER: DNA-dependent transcription of adenovirus genes in a soluble whole-cell extract. Proc. Nat. Acad. Sci. USA. 77: 3855-3859 (1980).

REHFELD, J. F.: Four basic characteristics of the gastrin-cholecystokinin-system. Amer. J. Physiol. 240: 255-266 (1981).

Takahashi, Y., K. Kato, Y. HaYashizaki, T. WaKa BaYashi, E. Ohtsuka, S. Matsui, M. IKehara and K. MatSubara: Molecular cloning of the human cholecystokinin gene by use of a synthetic probe containing deoxyinosine. Proc. Nat. Acad. Sci. USA. 82: 1931-1935 (1985).

Vanderhaegen, J. J. and J. N. Crawley: Neuronal cholecystokinin (Ann. New York Acad. Sci. Vol. 488). The New York Acad. Sci., New York, 1985.

Prof. emer. Yasuo TAKAHASHI Department of Neuropharmacology Brain Research Institute, Niigata University Asahimachi, Niigata 951 Japan 